\title{
Degradation of long-chain $n$-alkanes in soil microcosms by two actinobacteria
}

\author{
CLAUDIO DE PASQUALE ${ }^{1}$, ERISTANNA PALAZZOLO ${ }^{1}$, LUCA LO PICCOLO $^{2}$ and PAOLA QUATRINI ${ }^{2}$ \\ ${ }^{1}$ Dipartimento dei Sistemi Agro-Ambientali ( $S A g A$ ), Università degli Studi di Palermo, Palermo, Italy \\ ${ }^{2}$ Dipartimento di Scienze e tecnologie Molecolari e Biomolecolari, Università degli Studi di Palermo, Palermo, Italy
}

The ability of two recently isolated actinobacteria, that degrade medium and long chain $n$-alkanes in laboratory water medium, was investigated in soil microcosms using different standard soils that were artificially contaminated with $n$-alkanes of different length $\left(\mathrm{C}_{12}-\mathrm{C}_{20}-\mathrm{C}_{24}-\mathrm{C}_{30}\right)$. The two strains, identified as Nocardia sp. SoB and Gordonia sp. SoCp, revealed a similar high HC degradation efficiency with an average of $75 \%$ alkane degraded after 28 days incubation. A selectivity of bacteria towards $n$-alkanes of different length was detected as well as a consistent effect of soil texture and other soil physical chemical characteristics on degradation. It was demonstrated the specific aptitude of these selected strains towards specific environmental conditions.

Keywords: Bioremediation, soil microcosms, GC-MS, n-alkanes, Nocardia, Gordonia.

\section{Introduction}

Bioremediation, defined as the use of various organisms to detoxify or remove pollutants, is an emerging method for the degradation of many environmental organic pollutants, including those resulting from the petroleum industry. ${ }^{[1-3]}$ When bioremediation can be carried out in situ, it appears as a cost-effective means to remove many of those chemical pollutants that adversely impact human health and environmental quality. Various organisms, especially bacteria, are able to degrade HCs and can be used to detoxify and remove pollutants in various "in situ" treatments. The success of biodegradation depends on several factors.

Among them, specific metabolic capabilities of microbes and bioavailability of the contaminating compound as well as its chemical structure are very remarkable. ${ }^{[4]}$

Mixtures of HCs, including those resulting from oilrefining processes, are often extremely complex. In fact, they may contain variable amounts of different components such as saturated HCs, cyclic alkanes, mono-, di- and aromatic compounds bearing various degrees of substitution, unsaturated $\mathrm{HCs}$ such as $n$-alkenes, iso-alkenes, and cyclic alkenes. $^{[5]}$

Address correspondence to Claudio De Pasquale, Università degli Studi di Palermo, Dipartimento dei Sistemi AgroAmbientali (SAgA) Ed. 4, viale delle Scienze 90128, Palermo, Italy; E-mail: claudio.depasquale@unipa.it

Received May 7, 2011.
Although it is well known that unsaturated HCs do not occur in natural oils, they are, however, formed in variable amounts during thermal and catalytic cracking processes. The biodegradation degree of aliphatic $\mathrm{HC}$ is typically lower than that of aromatics; nevertheless most studies have focussed on the fate and behaviour of aromatic compounds in soil. Alkanes are non-polar virtually water insoluble $\mathrm{HC}$ that interact with the soil mineral and organic fraction reducing their chemical and biological availability. Understanding the microbial ecology and biodegradation constraints of oil contaminated sites in different environments, would help to find the best degrading conditions, resulting in a complete environmental cleanup.

HCs degraders have been isolated from contaminated and pristine soils. Most are Bacteria belonging to the $\alpha$-, $\beta$ - and $\gamma$-Proteobacteria and to the Actinomycetales (high G+C Gram-positive bacteria). ${ }^{[6]}$ Pseudomonas putida GPo1 was the most extensively characterized strain for alkane degradation. Here a membrane-bound monooxygenase (encoded by alkB), and soluble rubredoxin and rubredoxin reductase, convert the alkane into the corresponding alcohol that is further oxidized to aldehyde and acid, prior to proceeding into the $\beta$-oxidation pathway. Depending on the $\mathrm{HC}$ molecules, other degradation pathways have also been elucidated. ${ }^{[7,11]}$ Different enzymatic systems may be involved in the degradation of the highest and lowest molecular weight HCs respectively. ${ }^{[12]}$

Oil-contaminated sites are dominated by Gram-negative bacteria. ${ }^{[13,14]}$ Our previous study on assessment of bioremediation potential of a contaminated site, ${ }^{[15]}$ revealed that Gram-positive actinomycetes are dominating in harsh and 
arid environments suggesting that they might be a good alternative to the most studied Gram-negative strains for HC degradation. Gram-positive alkane degraders have been also detected in uncontaminated soils, they are generally adapted to resource-limited conditions and do not fluctuate in response to the addition of a $\mathrm{C}$ source such as HC. ${ }^{[16-18]}$

Recently, five Gram-positive $\mathrm{G}+\mathrm{C}$ rich actinobacteria have been isolated from oil -contaminated Sicilian beach. The bacteria were found able to degrade long-chain $n$ alkanes up to hexatriacontane. ${ }^{[15]}$ The present study reports about the ability of two isolates, Nocardia sp. SoB and Gordonia sp. SoCp, in degrading medium and long chain $n$-alkanes $\left(n \mathrm{C}_{12}, n \mathrm{C}_{20}, n \mathrm{C}_{24}, n \mathrm{C}_{30}\right)$ in artificially contaminated soil microcosms. Standard soils with different physical-chemical characteristics were used in order to evaluate the effects of environmental parameters on degradation of $n$-alkanes added as pure or mixed solutions. The strains were inoculated in the contaminated microcosms singly and in consortium. The aim of this work is to check the possibility to use these strains as bio-degraders in HC contaminated soil sites characterized by different conditions and to detect the main environmental factors that influence $\mathrm{HC}$ degradation in soil. The study evidence different degradation paths for each considered compound considering the microcosm conditions related to the soil's physicochemical chacteristics.

\section{Materials and methods}

\section{Experimental design}

Surface standard soils were purchased from Landwirtschaftiche Untersuchungs und Forschhungsanstalt (LUFA) Speyer (Germany) and their physico-chemical characteristics are listed in Table 1 . Soils were aliquot into glass dishes to give soil layers of $<2 \mathrm{~cm}$ thickness, and the dishes, covered with aluminium foil, were sterilized in a Fedegari autoclave (Type FVS 9110E, Tecnomara, Italy) for 20 minutes at $121 \pm 1^{\circ} \mathrm{C}$. The procedure was repeated twice, with a 24-hour incubation period in a laminar flow unit at room temperature, and afterwards, the samples were considered to be sterile and stored and handled under sterile conditions in a laminar flow unit.

Linear $\mathrm{HC} n \mathrm{C}_{12}, n \mathrm{C}_{19}, n \mathrm{C}_{20}, n \mathrm{C}_{24}$, and $n \mathrm{C}_{30}$ (HCs) all 99\% purity grade were obtained by Fluka, Sigma-Aldrich Chemie, Switzerland. Hexane (HPLC fluorescence grade) was purchased from Fisher Scientific. Standard solutions of $n$-alkanes $\mathrm{C}_{12}, \mathrm{C}_{20}, \mathrm{C}_{24}$, and $\mathrm{C}_{30}$ in hexane $(1000 \mu \mathrm{g}$ $\mathrm{mL}^{-1}$ ) were used during the study as $\mathrm{HC}$ contaminants. Hexane was chosen as solvent after checking that it was neither toxic to the bacterial strains nor used as a growth substrate.

Soil microcosms were set in $15 \mathrm{~mL}$ polypropylene conical sterile tube (Falcon, $2 \mathrm{~g}$ of air dried soil per tube) and artificially contaminated with $1 \mathrm{~mL}$ of the single $\mathrm{HC}$ solutions, or with $1 \mathrm{~mL}$ of the solution mixture $\left(n \mathrm{C}_{12}, n \mathrm{C}_{20}\right.$, $\left.n \mathrm{C}_{24}, n \mathrm{C}_{30}\right)$ at a concentration of $1000 \mu \mathrm{g} \mathrm{mL}^{-1}$ each. In order to get a good and homogeneous distribution of contaminants in the soil microcosms, the $\mathrm{HC}$ solutions were added to soil systems in a rotary agitator for 48 hours at $20^{\circ} \mathrm{C}$ and $30 \mathrm{rev} \mathrm{min}^{-1}$. The hexane residue was then evaporated by a gentle nitrogen stream at $20^{\circ} \mathrm{C}$ with $3 \mathrm{~mL} \mathrm{~min}^{-1}$ gas flow.

After the contamination step, soils were inoculated with the bacterial cultures as described in the following section. Abiotic control tubes (without bacterial inoculation) were set in order to evaluate the oxidation processes of contaminants in the absence of bacteria. The soil microcosms were incubated at $30^{\circ} \mathrm{C}$ for 28 days, during which soil moisture according to weight was maintained at $50 \%$ of their WHC by adding sterile distilled water when necessary. All treatments were repeated in triplicates. Combining five different contamination conditions $\left(n \mathrm{C}_{12}, n \mathrm{C}_{20}, n \mathrm{C}_{24}, n \mathrm{C}_{30}\right.$ and Mix solution), four inoculation treatments (Nocardia, Gordonia, Nocardia + Gordonia, and not inoculated) and four soils (see Table 1) a total of two hundred forty tubes were set and taken into account for the evaluation of HCs degradation.

Table 1. Soil physicochemical characteristics.

\begin{tabular}{|c|c|c|c|c|}
\hline Standard soil type no. & 2.1 & 2.2 & 2.3 & $6 S$ \\
\hline \multicolumn{5}{|l|}{ Physicochemical characteristics } \\
\hline \multicolumn{5}{|c|}{ Particle size $(\mathrm{mm})$ distribution according to USDA (\%) } \\
\hline Loam $\%$ & $8.7 \pm 2.2$ & $13.5 \pm 2.3$ & $29.8 \pm 3.2$ & $36.0 \pm 2.6$ \\
\hline Sand $\%$ & $87,6 \pm 1.9$ & $79.1 \pm 3.3$ & $61.0 \pm 3.2$ & $21.9 \pm 1.6$ \\
\hline Soil type & sand & loamy sand & sandy loam & clay \\
\hline $\mathrm{pH}(0.01 \mathrm{M} \mathrm{CaCl})$ & $6.0 \pm 0.7$ & $5.6 \pm 0.4$ & $6.2 \pm 0.3$ & $7.0 \pm 0.2$ \\
\hline Cation exchange capacity(meq / 100g) & $6 \pm 3$ & $11 \pm 2$ & $9 \pm 1$ & $20 \pm 3$ \\
\hline Water holding capacity $(\mathrm{g} / 100 \mathrm{~g})$ & $35.1 \pm 4.0$ & $48.0 \pm 3.0$ & $34.9 \pm 3.0$ & $42.3 \pm 2.8$ \\
\hline Weight per volume $(\mathrm{g} / 1000 \mathrm{ml})$ & $1380 \pm 38$ & $1170 \pm 52$ & $1315 \pm 84$ & $1245 \pm 78$ \\
\hline
\end{tabular}




\section{Bacterial inoculation}

After HCs contamination and immediately after hexane evaporation, soil microcosms were inoculated with the two alkane-degrading bacterial strains Nocardia sp. SoB and Gordonia sp. SoCp, previously isolated in our laboratory. ${ }^{[15]}$ The two strains were grown for two days in mineral Bushnell-Haas broth (BH, Difco) with $1 \% n$-hexadecane as sole $\mathrm{C}$ source to a concentration of $10^{9} \mathrm{CFU}$ (ColonyForming Units) $\mathrm{mL}^{-1}$ and inoculated alone $(500 \mu \mathrm{L})$ or co-inoculated ( $250 \mu \mathrm{L}$ each strain) in each microcosm tube. Sterile $\mathrm{BH}$ broth was added to the non inoculated control tubes (abiotic controls).

\section{Soil HC solvent extraction}

After incubation, the soil microcosms were shaken vigorously using a horizontal shaker (Universal Table Shaker 709) at $400 \mathrm{rev} \mathrm{min}{ }^{-1}$ for 10 minutes. Then, $10 \mathrm{~mL}$ hexane was added and the tubes were shaken in a mechanical rotary agitator for 2 hours at $20^{\circ} \mathrm{C} 80 \mathrm{rev} \mathrm{min}{ }^{-1}$. The tubes were centrifuged using a Mistral 2000 with a rotation radius of

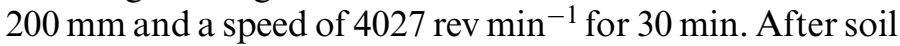
settling, the aliquot of the supernatant hexane phases were transferred in sample vials. The fraction was dried over 2 $\mathrm{g}$ of $\mathrm{Na}_{2} \mathrm{SO}_{4}$. The extraction was repeated twice and both fractions were collected in a $20 \mathrm{~mL}$ volumetric flask. Then, $100 \mu \mathrm{L}$ of a hexane solution of nonadecane $\left(10 \mu \mathrm{g} \mu \mathrm{L}^{-1}\right)$ was added as an internal standard in order to normalize the efficiency of the analytical procedures.

\section{GC-MS analysis}

GC-MS analyses were performed on a Hewlett-Packard 5890 GC system interfaced with an HP 5973 quadrupole mass spectrometer. An HP5-MS column was used (5\% diphenyl- $95 \%$ dimethylpolysiloxane $30 \mathrm{~m} \times 0.2 \mathrm{~mm}, 0.25$ $\mu \mathrm{m}$ film, J\&W Scientific, Folsom CA, USA). A $4 \mathrm{~mm}$ ID straight glass injector liner packed with glass wool was used. Analyses were carried out in splitless injection $(1 \mu \mathrm{L})$

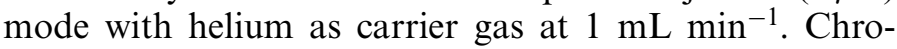
matographic conditions were: injector temperature $240^{\circ} \mathrm{C}$, oven temperature program 2 minutes of $150^{\circ} \mathrm{C}$ isotherm followed by a linear temperature increase of $5^{\circ} \mathrm{C} \mathrm{min}-1$ up to $280^{\circ} \mathrm{C}$ held for 10 minutes. The MS full-scan conditions were: source temperature $230^{\circ} \mathrm{C}$, interface temperature $280^{\circ} \mathrm{C}$. The electron impact ionization spectra were obtained at $70 \mathrm{eV}$, recording mass spectra from $\mathrm{m} / \mathrm{z} 42$ to 550.

HCs were identified with the NIST 2005 mass spectral database and confirmed by comparing mass spectra and retention times with those of standard compounds. A standard mixture of $n$-alkanes $\left(n \mathrm{C}_{12}-n \mathrm{C}_{30}\right)$ in hexane was used as an external standard to verify retention times (RT) for each compound and quantify the degradation paths.

The linearity of the analytical method as above describe was assessed and the recovery of solvent extractions was evaluated for each $n$-alkane and two standard soils $6 \mathrm{~S}$ and 2.1. The analytical recovery was tested at four concentrations, 1000, 100, 25 and $10 \mu \mathrm{g} \mathrm{mL}^{-1}$ and was 70-99\% (Fig. 1) and the solvent extraction of $\mathrm{HC}$ was constant at increasing concentrations. The limit of quantification (LOQ) was fixed using a standard grade $\mathrm{HC}$ solution $\left(0.1 \mu \mathrm{g} \mathrm{mL}^{-1}\right.$ each). The limit of detection (LOD) for each analysis was defined by measuring progressively more diluted concentrations of the studied HCs until a signal-to-noise ratio of $3: 1$ was reached. ${ }^{[19]}$

On the above-mentioned results, the quantitative amounts of each $n$-alkane residue after 28 days of incubation in microcosms were determined by the GC-MS method by using five points calibration curve with concentrations ranging from 0.5 to $50 \mu \mathrm{g} \mathrm{mL}^{-1}$. For each calibration curve the regression coefficient $\left(\mathrm{R}^{2}\right)$ was determined and linearity considered achieved when $\mathrm{R}^{2}$ was greater than 0.995 . The RSD for each compound was lower than $15 \%$.

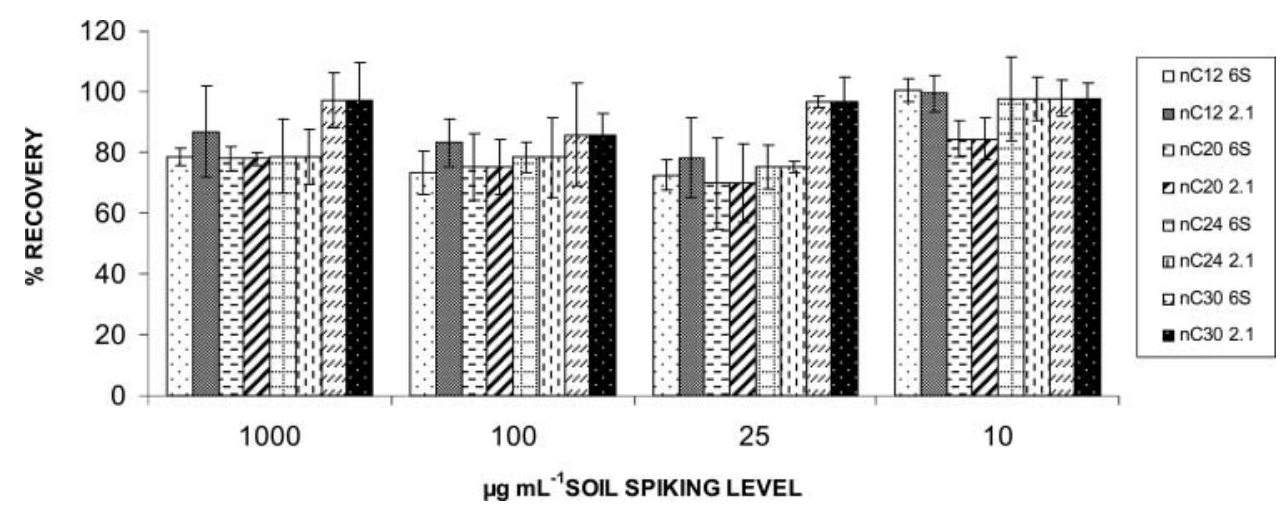

Fig. 1. Recovery of hydrocarbons $(\mathrm{HC})$ from spiked soils $(2.1 ; 6 \mathrm{~S})$; error bars represent the Standard deviation $(\mathrm{n}=3)$. 


\section{Statistical analyses}

The amounts of $\mathrm{HC}$ residues recovered from each microcosm after the incubation period were expressed in terms of $\mu \mathrm{g}$ and the relative standard deviation $\left(\mathrm{RSD}^{\%}\right)$ were also calculated and considered versus control samples. The amounts of $\mathrm{HC}$ recovered from each experimental condition were also analyzed by $t$-tests.

The effect of the microcosm environmental factors: single or consortium strain inoculum, soil types (\% of clay), single or mixed $\mathrm{HC}$ solution versus the $\mathrm{HCs}$ residues were compared by a multifactorial analysis of variance (MANOVA), and the means of residues were separated by the Student-Newman-Keuls pairwise multiple comparison procedure.

Principal component analysis (PCA) was applied to investigate the relationships between the physicochemical characteristics of soils and $n$-alkanes degradation. The HCs residues were considered as the dependent variable of the considered experimental parameters. Five variables were considered and the method of Pearson parametric correlation was used: $\mu \mathrm{g}$ of $\mathrm{HCs}$ residues after the incubation period in each microcosm, CEC, $\%$ particle size $<0.002$ $\mathrm{mm}, \% \mathrm{C}$ and $\mathrm{pH}$ of soils. The obtained principal components were considered as significative if their Eigen values were $>1$. All the statistical analyses were performed by using Statistica 6.0 for Windows (Stat Soft Italia).

\section{Results and discussion}

The extent to which a chemical partition into the organic matter is described by $\mathrm{K}_{\mathrm{oc}}$, but it may also be described by $\mathrm{K}_{\mathrm{ow}}$; aliphatic hydrocarbons can strongly be partitioned into organic matter and diffuse into the three-dimensional structure of the supramolecular organization of humic and fulvic substances which represent the most abundant fraction of soil organic matter. ${ }^{[20]}$ Hydrocarbons may be sequestered within the soil through sorption to organic matter and mineral fractions and/or diffuse into the three-dimensional structure of the soil. The degree to which these physical interactions occur increases with time, and has been termed 'ageing'. ${ }^{[21,22]}$

The average amount of the recovered $\mathrm{HC}$ in inoculated microcosms under the different experimental conditions after 28 days of incubation was $267.44 \mu \mathrm{g}$ corresponding to a degradation of $75 \%$.

$\mathrm{HC}$ residues found in soil microcosms contaminated with $n$-alkanes in single and mixed solution mode, inoculated with Nocardia sp. SoB, Gordonia sp. SoCp and the consortium (Nocardia + Gordonia), in soils 2.1, 2.2, 2.3 and $6 \mathrm{~S}$, respectively, are fully elucidated in Figure 2. The two bacterial strains have comparable degradation ability on each single $\mathrm{HC}$ showing a preference for the shortest $\left(\mathrm{C}_{12}\right)$ and the longest one $\left(\mathrm{C}_{30}\right)$ (Figs. $2 \mathrm{~A}, \mathrm{~B}, \mathrm{C}$; Fig. 4). HC degradation is clearly influenced by the soil type and the presence of other HCs. An increasing degradation trend is generally detectable in the four soils in the following order: $2.1<2.2<2.3<6 \mathrm{~S}$ (Fig. 4). Degradation of the long-chain alkane triacontane in microcosms contaminated with the $\mathrm{HC}$ mixture (Fig. $2 \mathrm{D}, \mathrm{E}$ ) is positively influenced by the presence of shorter alkanes suggesting that the latter may function as inducers of the catabolic enzymes. When the soils contaminated with the $\mathrm{HC}$ mixture are incubated with the consortium this effect is not detected probably due to competition between the two strains (Fig. 2F).

The PCA reduces the number of total variables to only few retaining the major part of the information on the systems variability. The amount of variables was reduced to only two (PC1 and PC2) which retained $86.1 \%$ of the total variance (Fig. 3). The soil with largest amount of clay (6S) retained positive score on PC1. Sandy soils $(2.1,2.2$, 2.3) were placed in the directly opposite position respect to soil 6S. Moreover soil 2.2 was separated from 2.1 and 2.3 by the increase of SOC content and CEC on PC2. The HC degradation increases with the increase of $\mathrm{pH}, \mathrm{SOC}, \mathrm{CEC}$ and with the decrease of soil particle size.

The MANOVA results were $F=89.1, d f=3, P<0.001$; $F=151.15, d f=3, P<0.001 ; F=6.94, d f=1 ; P<0.001$ for soil clay $\%$, linear HC compound residues, and mixed or single solution experimental factors used to contaminate soil microcosms, respectively. The interaction among all factors (soil clay $\% * \mathrm{HC}^{*}$ solution type) was also significant $(F=4.81, d f=9, P<0.001)$ (Fig. 4). The interaction between factors (bacterial strain* $\mathrm{HC}^{*}$ solution type) was not significant $(F=0.17, d f=6, P=0.98437)$. The environmental complexity of soil systems requires the screening of several parameters, both chemical and physical, each showing a significant overall multivariate effect on the degradation of HCs.

The percentage of soil clay, $\mathrm{HC}$ compounds and the solution, mixed or single used to contaminate soil microcosms, showed significant influence on the long-chain HC degradation. Moreover it was evidenced how different parameters related to the environment can relevantly affect the degradation of the organic pollutant.

Soil $6 \mathrm{~S}$ revealed the highest degradation rate of all $\mathrm{HC}$ (Fig. 2, Fig. 4) probably due to neutral pH, higher CEC and higher clay content as compared with the other soils. The higher clay contents are associated with high surface areas which allow a better interaction between supramolecular aggregates and aliphatic hydrocarbons. Natural organic matter is, in turn, a good substrate for bacterial growth. Moreover clay soil systems are also characterized by larger porosities. ${ }^{[23,24]}$ These favour better air and water circulation. Good air/water circulation is the factor which enhances bacterial growth. Our results appear to confirm previous data by Ghazali et al., ${ }^{[25]}$ showing that larger amount of sand particles in soils disadvantage the microbial biomass growth. The HCs residues confirm how the environmental parameters directly affect the bioremediation result. 

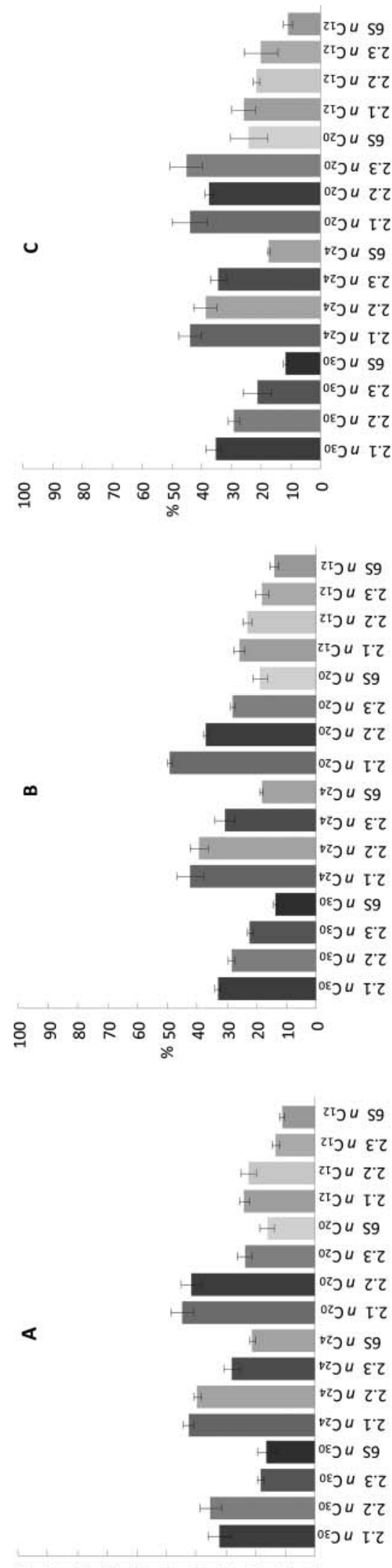

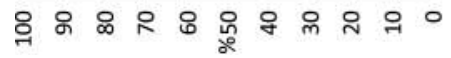

4

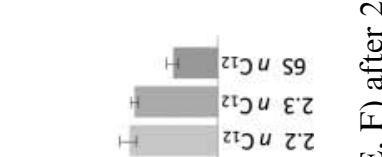

ध่

记

호

赵

在

를

के

U

$\infty$ \&

这

0

웡

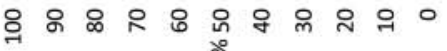

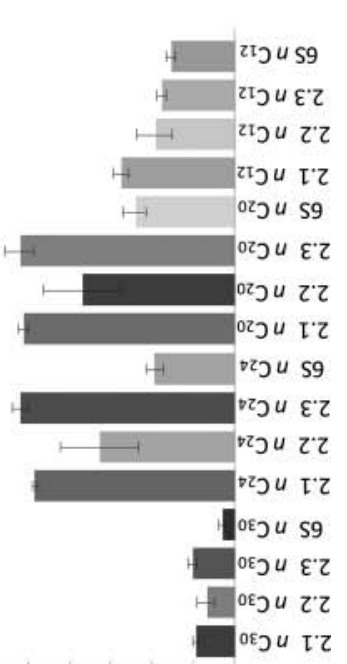

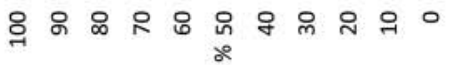

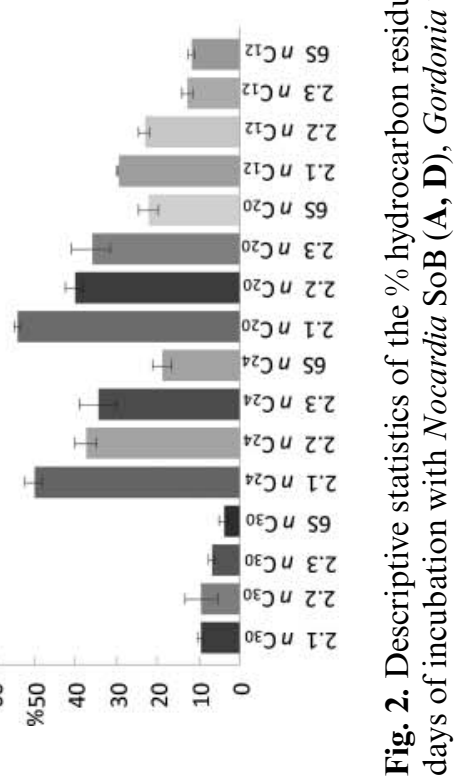




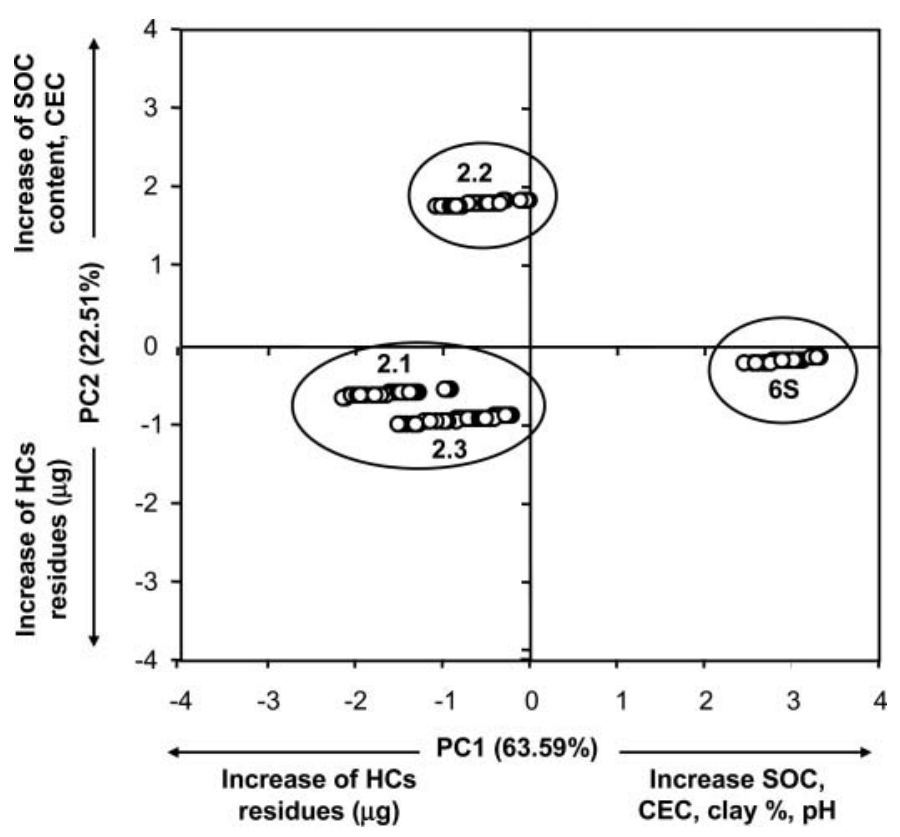

Fig. 3. Principal component analysis (PCA) graph representation of the soils physicochemical characteristics and $\mathrm{HCs}$ residues after the incubation period $(n=3)$.
The two strains inoculated did not behave differently in their degradation efficiency. The interaction between factors (bacterial strain* $\mathrm{HC}^{*}$ solution type) was not statically significant. These data are consistent considering similar degradation rate of each strain. The initial step in the aerobic degradation of saturated, aliphatic ( $n$-alkanes) compounds involves the oxygenase enzyme 'attacking' the terminal methyl group where a primary alcohol is formed. ${ }^{[8,26,27]}$

Both strains were isolated from a $\mathrm{HC}$ contaminated sandy soil in Sicily and confirmed in all kinds of soils the degradation ability on medium and long chain $\mathrm{HC}$ that was already detected in mineral medium. ${ }^{[15]}$ This ability depends on the presence of one or more AlkB-like alkanehydroxylase systems that were detected in both strains ${ }^{[15]}$ and likely, on other undetected systems. In Nocardia SoB three quite divergent $a l k B$ sequences were detected by PCR using degenerated primers. It can be hypothesized that each system is involved in degradation of alkanes of different length. Gordonia SoCp and its "companion" isolate $\mathrm{SoCg}$ carry a single alk $B$ gene in their chromosome that encodes an AlkB-type alkane hydroxylase involved in degradation of hexadecane and triacontane. ${ }^{[28]}$ The two strains inoculated in the microcosms may use different strategies to cope with $\mathrm{HC}$ of different length both reaching a similar

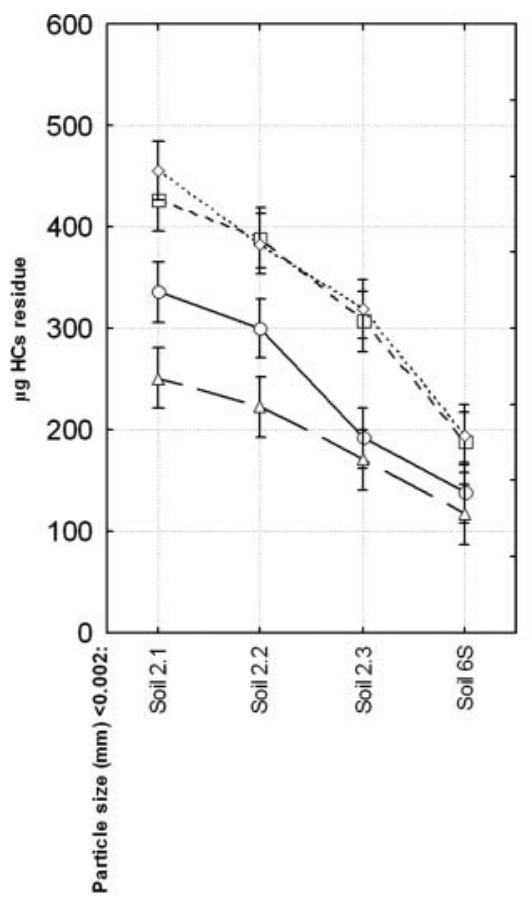

A

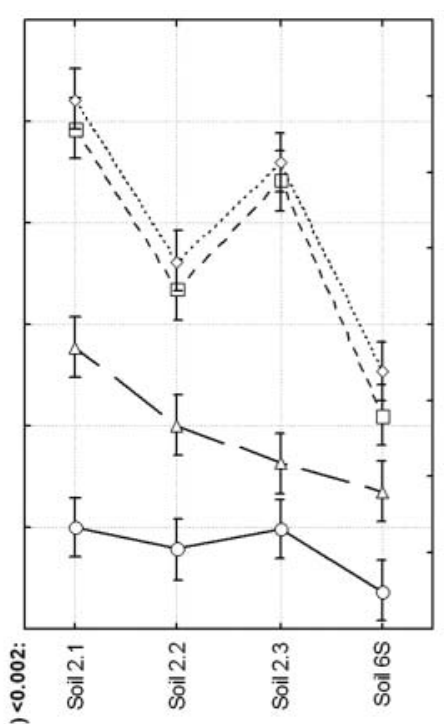

$\begin{array}{ll}-\infty \text { Compound } & C_{30} \\ -\square-\text { Compound } & C_{24} \\ \ldots . \text { Compound } & C_{20} \\ -\triangle \text {. Compound } & C_{12}\end{array}$ B

Fig. 4. Amount of hydrocarbons $(\mu \mathrm{g})$ recovered from soils systems spiked with (A) single or (B) a mixture of HC after incubation with Gordonia, Nocardia and the bacterial consortium. Soil types were considered by their clay $\%$ content (particle size $<0.002 \mathrm{~mm}$ ). Error bars represent confidence values at the $95 \%$ confidence level. The $P$-value is the result of Multifactorial Analysis of Variance (MANOVA). 
degradation rate depending on the supramolecular organic aggregate.

\section{Conclusions}

In the present study two HC degrading bacterial strains were used on different soils to show how soil-contaminant interactions can affect microbial degradation. Our study has demonstrated as hydrocarbons biodegradation in soils is controlled by hydrocarbon physico-chemistry, environmental conditions, bioavailability and the presence of catabolically active microbes. Gordonia and Nocardia genera appear to be particularly promising strains for aliphatic hydrocarbon bioremediation programs in all kinds of soils and in particular in those with large clay content. They are suitable for $\mathrm{HC}$ degradation because of their drought resistance ability. ${ }^{[29,30]}$ Moreover considering the promising results obtained by the selected degraders in different environmental conditions, they may be capable tools in polluted environments for bioaugmentation practices in clay and arid soils.

\section{Acknowledgments}

The authors acknowledge Professor Stefano Colazza and Giuseppe Alonzo (University of Palermo) for their kind scientific cooperation. This study was partly supported by the Italian Ministry of Education, University and Research (MIUR ex 60\%, 2007).

\section{References}

[1] Iwamoto, T; Nasu, M. Current bioremediation practice and perspective. J. Biosci. Bioeng. 2001, 92, 1-8.

[2] Watanabe, K. Microorganisms relevant to bioremediation. Curr. Opin. Biotechnol. 2001, 12, 237-241.

[3] Philip, J.C.; Bamforth, S.M.; Singleton, I.; Atlas, R.M. Environmental pollution and restoration: a role for bioremediation. In: Bioremediation, Atlas, R.M., Philip, J. Eds. ASM Press, Washington DC, 2005.

[4] Volkering, F.; Breure, A.M.; Rulkens, W.H. Microbiological aspects of surfactant use for biological soil remediation. Biodegradation 1998, 8, 401-417.

[5] Mcbride, M.B. Environmental Chemistry of Soils. Oxford University Press, New York, 1994.

[6] Van Beilen, J.B.; Funhoff, E.G.; Van Loon, A.; Just, A.; Kaysser, L.; Bouza, M.; Holtackers, R.; Röthlisberger, M.; Li, Z.; Witholt, B. Cytochrome P450 alkane hydroxylases of the CYP153 family are common in alkane-degrading eubacteria lacking integral membrane alkane hydroxylases. Appl. Environ. Microbiol. 2006, 72, 59 -65 .

[7] Falatko, D.M., Novak, J.T. Effects of biologically produced surfactants on the mobility and biodegradation of petroleum hydrocarbons. Water Environ. Res. 1992, 64, 163-169.

[8] Van Hamme, J.D.; Singh, A.; Ward, O.P. Recent advances in petroleum microbiology. Microbiol. Mol. Biol. Rev. 2003, 67, 503-549.
[9] Habe, H.; Omori, T. Genetics of polycyclic aromatic hydrocarbon metabolism in diverse aerobic bacteria. Biosci. Biotechnol. Biochem. 2003, 67, 225-243.

[10] Van Beilen, J.B.; Panke, S.; Lucchini, S.; Franchini, A.G.; Rothlisberger, M.; Witholt, B. Analysis of Pseudomonas putida alkane-degradation gene clusters and flanking insertion sequences: evolution and regulation of the alk genes. Microbiology 2001, 147, $1621-1630$

[11] Wentzel, A.; Ellingsen, T.E.; Kotlar, H.K.; Zotchev, S.B.; Holst, M.T. Bacterial metabolism of long-chain $n$-alkanes. Appl. Microbiol. Biotechnol. 2007, 76, 1209-1221.

[12] Van Beilen, J.B. and Funhoff, E.G. Alkane hydroxylases involved in microbial alkane degradation. Appl. Microbiol. Biotechnol. 2007, $74,13-21$.

[13] Macnaughton, S.J.; Stephen, J.R.; Venosa, A.D.; Davis, G.A.; Chang, Y.J.; White, D.C. Microbial population changes during bioremediation of an experimental oil spill. Appl. Environ. Microbiol. 1999, 65, 3566-3574.

[14] Röling, W.F.; Milner, M.G.; Jones, D.M.; Fratepietro, F.; Swannell, R.P.; Daniel, F. Bacterial community dynamics and hydrocarbon degradation during a field scale evaluation of bioremediation on a mudflat beach contaminated with buried oil. Appl. Environ. Microbiol. 2004, 70, 2603-2613.

[15] Quatrini, P.; Scaglione, G.; De Pasquale, C.; Riela, S.; Puglia, A.M. Isolation of Gram-positive n-alkane degraders from an hydrocarbon-contaminated Mediterranean shoreline. J. Appl. Microbiol. 2008, 104, 251-259.

[16] Heiss-Blanquet, S.; Benoit, Y.; Marechaux, C. and Monot, F. Assessing the role of alkane hydroxylase genotypes in environmental samples by competitive PCR. J. Appl. Microbiol. 2005, 99, 1392-1403.

[17] Kloos, K.; Munch, J.C.; Schloter, M. A new method for the detection of alkane-monooxygenase homologous genes (alkB)in soils based on PCR-hybridization. J. Microbiol. Meth. 2006, 66, 486 $-496$.

[18] Margesin, R.; Labbe, D.; Schinner, F.; Greer, C.W.; Whyte, L.G. Characterization of hydrocarbon-degrading microbial populations in contaminated and pristine Alpine soils. Appl. Environ. Microbiol. 2003, 69, 3085-3092.

[19] Armbruster, D.A.; Tillman, M.D.; Hubbs, L.M. Limit of detection (LQD)/limit of quantitation (LOQ): comparison of the empirical and the statistical methods exemplified with GC-MS assays of abused drugs. Clin. Chem. 1994, 40, 1233-1238.

[20] De Pasquale, C.; Fodale, R.; Giulivi, M.; Conte, P.; Alonzo, G. HS-SPME and GC-MS as valid tools to assess volatile organic compounds from soil natural organic matter. Chem. Listy 2008, 102, s265-s1311.

[21] Hatzinger, P.B., Alexander, M. Effect of ageing of chemicals in soil on their biodegradability and extractability. Environ. Sci. Technol. 2005, 29, 537-545.

[22] Stroud, J.; Paton, G.; Semple, K. Microbe aliphatic hydrocarbon interactions in soil. J. Appl. Microbiol. 2007, 102, 1239 $-1253$.

[23] Hill, R.L.; Horton, R.; Cruse R. M. Tillage effects on soil water retention and pore size distribution of two mollisols. Soil Sci. Soc. Amer. J. 1985, 49, 1264-1270.

[24] Nimmo, J.R. Modeling Structural influences on soil water retention. Soil Sci. Soc. Amer. J. 1997, 61, 712-719.

[25] Ghazali, F.M.; Rahman, R.N.Z.A.; Salleh, A.B.; Basri, M. Biodegradation of hydrocarbons in soil by microbial consortium. Inter. Biodeterior. Biodegrad. 2004, 54, 61-67.

[26] Sepic, E.; Leskovsek, H.; Trier, C. Aerobic bacterial degradation of selected polyaromatic compounds and n-alkanes found in petroleum. J. Chromatogr. A 1995, 697, 515 -523 .

[27] Koma, D.; Hasumi, F.; Yamamoto, E., Ohta, T.; Chung, S.Y.; Kubo, M. Biodegradation of long-chain n-paraffins from waste oil 
of car engine by Acinetobacter sp. J. Biosci. Bioeng. 2001, 91, 94 $-96$.

[28] Lo Piccolo, L., De Pasquale, C.; Fodale, R.; Puglia, A.M.; Quatrini, P. Involvement of an alkane hydroxylase system of Gordonia sp. strain $\mathrm{SoCg}$ in degradation of solid n-alkanes. Appl. Environ. Microbiol. 2011, 77, 1204 -1213 .
[29] Luz, A.P.; Pellizari, V.H.; Whyte, L.G.; Greer, C.W. A survey of indigenous microbial hydrocarbon degradation genes in soils from Antarctica and Brazil. Can. J. Microbiol. 2004, l50, 323-333.

[30] Amouric, A.; Verhe, F.; Auria, R.; Casalot L. Study of a hexanedegrading consortium in a biofilter and in liquid culture: biodiversity, kinetics and characterization of degrading strains. FEMS Microbiol. Ecol. 2006, 55, 239-247. 